\title{
3D RECORDING OF UNDERWATER ANTIQUITIES IN THE SOUTH EUBOEAN GULF
}

\author{
E. Diamanti ${ }^{1}$, F. Vlachaki ${ }^{1}$ \\ ${ }^{1}$ Hellenic Institute of Marine Archaeology (H.I.M.A.), ienae@otenet.gr, Saripolou 9, Athens, Greece
}

\section{Commission V}

KEY WORDS: underwater photogrammetry, underwater cultural heritage, marine archaeology, visualization, 3D modeling, orthophotomosaics, South Euboean Gulf archaeological survey, H.I.M.A.

\begin{abstract}
An underwater archaeological survey was initiated in 2006 by the Hellenic Institute of Marine Archaeology in collaboration with the Ephorate of Underwater Antiquities of Greece, in the South Euboean Gulf. The survey is being conducted under the direction of the archaeologist Dr G. Koutsouflakis and in the course of the project important shipwrecks of Classical, Roman, and Byzantine periods have been brought to light, adding tangible evidence on ancient seafaring and maritime trade. The South Euboean Gulf archaeological survey has presented many challenges to the documentation team of H.I.M.A, and has served as a case-study for 3D recording applied on ancient wrecks, found at medium depths $(22-47 \mathrm{~m})$ and under the conditions that are imposed during an archaeological survey of a certain geographical region. This paper focuses on the implementation of photogrammetric and geodetic techniques used for acquisition and processing of collected data, in order to generate 3D models for six different wrecks, resulting in a fast, reliable and cost efficient method to record underwater archaeological sites.
\end{abstract}

\section{INTRODUCTION}

The Hellenic Institute of Marine Archaeology (H.I.M.A.) is a private, non-profit organization, founded in 1973, whose aim is to undertake marine archaeological research under the supervision or in cooperation with the Greek Ministry of Culture. It has over 100 members, with diverse academic credentials, all of whom work on a voluntary basis.

3D recording of underwater archaeological sites has been applied to numerous projects that have been carried out by the documentation team of H.I.M.A. Among the main goals of this work, have been the generation of high resolution textured 3D models of sites found during a survey campaign, as well as the support of underwater archaeological excavations, with daily updated 2D plans, surface models and semantically augmented reconstructed 3D models which incorporate archaeological information.

The South Euboean Gulf was selected as a case-study for the location and evaluation of an expectedly great number of wrecks in a certain geographical region of significant archaeological importance. The selection of the survey area, by the director of the project G. Koutsouflakis, was not randomly made (Koutsouflakis, 2013). The north and south Euboean Gulfs, always served as the natural avenue of transmarine communication from the north to south Aegean and vice versa (Fig.1), as the east coast of Euboea is exposed to the strong northern winds blowing throughout the year and is generally avoided. The South Euboean Gulf is also adherent to the land of Attica and is the sea that connects cities that played a very important role in ancient Greece, as Athens, Chalcis and Eretria. The survey area extends from Chalkis to Kaferea and Sounion covering 465 square nautical miles

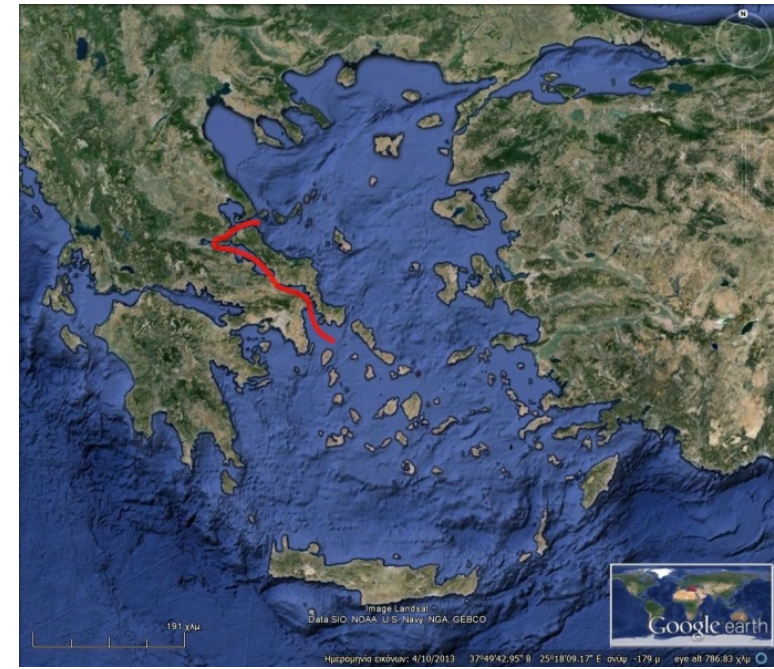

Figure 1: Sea route through the Euboean Gulf

In the course of this ongoing project 26 ancient wreck sites have been located so far, documented and preliminary evaluated. During the initial planning of the archaeological survey of this vast area, two main approaches were implemented: most of the wrecks are found close to the coast, at shallower waters (Koutsouflakis, 2013) and the research was going to be carried out by divers (archaeologists and other specialists) and not through the use of underwater surveying devices (Koutsouflakis, 2013). The first years of the project (2006-2010), wrecks were located and preliminary documented using conventional architectural drawings and sketches in combination with multiple trilateration methods and the production of photo mosaics. Since 2010 most of the 
important wreck sites were documented with the use of photogrammetry.

Underwater photogrammetry, along with computer vision science, provides a wide research field that can support a really low-cost procedure, nonetheless an extremely accurate result of a 3D model. One of the most important advantages of photogrammetry applied in underwater surveys, in comparison to other techniques, consists in its simplicity of implementation and the diversity of potential results (Drap, 2011). DSLR cameras and commercial software, that perform structure from motion (SfM) algorithms, thus producing a relatively fast $3 \mathrm{D}$ reconstruction of an object, were used for such purposes. Extraction of dense textured point clouds, 3D textured surfaces and high resolution orthophotomosaics served the challenging and demanding needs of an underwater archaeological survey.

\section{UNDERWATER ARCHAEOLOGICAL SITES IN THE SOUTH EUBOEAN GULF - CASE STUDIES}

Since 2010, the archaeological research was focused around the small island of Makronisos (Fig. 3, wrecks No 16, 17, 18, 24, 26) but also revisited wrecks that required detail documentation (Wreck No 6). During this period the main factors that influenced the framework of the 3D recording techniques and applied methodologies were:

- $\quad$ low budget research expeditions

- limited time on each new wreck site

- limited bottom dive time, on sites located at large depths

- the need for experienced 3D surveyors who also have knowledge and experience in technical diving

- difficult weather and underwater conditions

- the need for sufficient archaeological documentation and evaluation of located and recorded sites

- $\quad$ precision in $3 \mathrm{D}$ recording of diverse wreck sites

- qualitative data acquisition and generation of 3D models of potential underwater excavation sites

- on site generation of 3D models of wrecks

- on site generation of 2D plans that serve as a tool in everyday work during an underwater archaeological research project

- further processing of acquired data at a second stage for the generation of high quality $3 \mathrm{D}$ models

One of the main challenges of this project was the fact that each wreck had to be approached through a specific recording methodology due to the different on site conditions. Shallow or deep waters, flat or rocky sea-beds, excellent or poor visibility, pointed to multiple methods of data collection and processing. Flat sea-beds, like the ones of shipwrecks No 18 and 24 , both at approximately 40 meters, offered diving and photo shooting ease to the team. On the contrary, shipwrecks No 16,17 and 26, situated at almost inaccessible locations, demanded that the hours spent underwater should be kept at a minimum.

\subsection{Wreck No. 6}

The first 3D photogrammetric documentation of the South Euboean project was applied on wreck No. 6, a Hellenistic (2nd - 1st century B.C.), $18 \mathrm{mx} 7 \mathrm{~m}$ shipwreck, found at a depth of $39-47 \mathrm{~m}$. Due to the great interest of the ship's cargo (intact, mainly Brindisi type amphorae, parts of luxurious bronze furniture, bronze parts of the harness of the ship, a small part of the dress of a bronze statue, two sections of the wooden hull of the vessel) (Koutsouflakis, 2013), it was decided by the research team that a detailed documentation of the wreck would also serve as the basis for a systematic excavation at a later date. Thus, on this wreck, an underwater control points network was established, and measured with tape trilateration adjustment, while Plexiglas strips with coded targets, were used to increase the number of common points on the sea-bed. Photo acquisition was carried out using a common SONY DSLR A700 camera in a waterproof Ikelite housing. Among the software that was used for surveying of the site and photogrammetry processing, were Site Recorder SE, Eos Systems Photomodeler, Intergraph's ISAT \& ISSD, Rhinoceros and Autodesk's 3d Studio max. A Digital Surface Model was extracted and an orthophotomosaic of the shipwreck was produced. The 3D reconstruction of the site (Fig. 3) was however produced using Photomodeler and Rhinoceros as a combination of the theoretical models of the various finds and their photogrammetrically measured attributes. (Diamanti et.al, 2011).

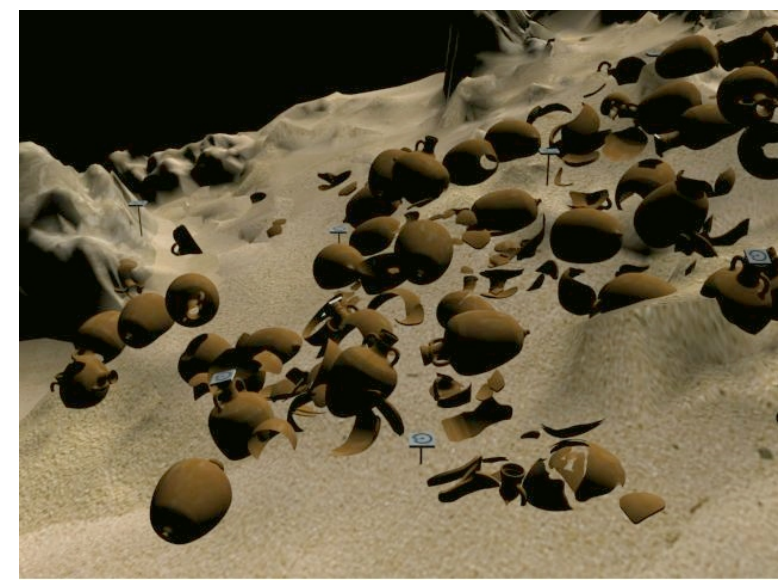

Figure 2: 3D rendered model of wreck No. 6, 3DS max, CH.I.M.A., E. Diamanti

\subsection{Makronisos' Ancient shipwrecks}

Underwater archaeological surveying along the small island of Makronisos was held during three research periods (2011, 2012, 2013), each of them lasting 15 days. During those periods, the 5 wrecks that were located, (Fig. 3, No.16, 17, 18, 24, 26), were all geometrically documented. Apart from shipwreck No.24, where a control points network was established for excavation purposes, the photogrammetric methodology followed was quite similar in all of them. Scale bars were placed on the sea-bed during photo acquisition sessions, so that the scale of the object could be defined and submerged buoys were used, so that a vertical axis could be determined. 


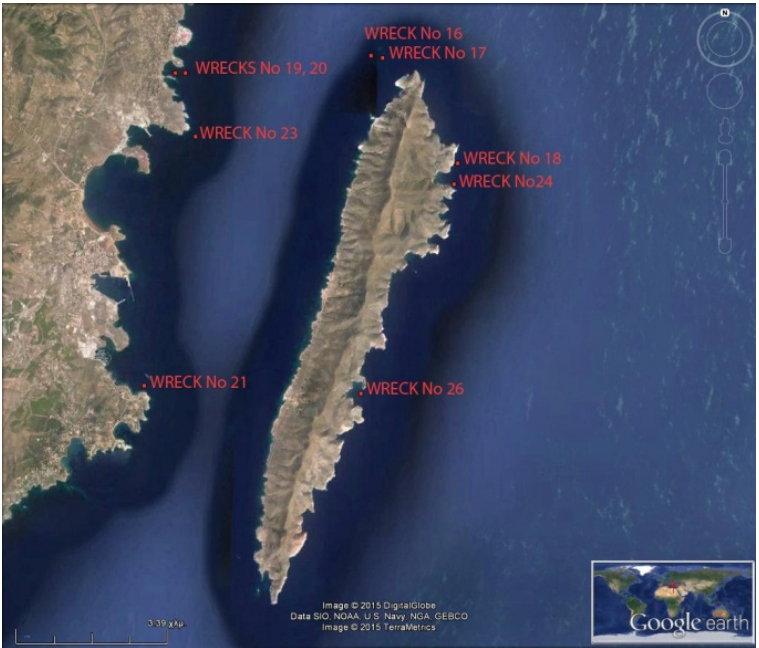

Figure 3:Locations of shipwrecks, Makronisos Island, (C) H.I.M.A.

The main software used during the documentation process were Agisoft Photoscan, ISTI-CNR MeshLab, Quantum GIS, Autodesk AutoCAD and $3 \mathrm{H}$ Consulting Site Rerorder. MeshLab is a open-source tool to handle 3D models (visualization, measurements etc). AutoCAD was used for the creation of semantically augmented 2D plans from orthophotos. Q-GIS was used to manage all 2D data (orthophotos, 2D drawings). Site Recorder was applied for trilateration computations. Photoscan was used for all the photogrammetric process, consisting of, block of images alignment, image matching, 3D point cloud extraction, 3D mesh creation and texturing. Photoscan uses an automated workflow for the aforementioned levels of the photogrammetric process. It is considered a user-friendly software not only for photogrammetrists, but also for archaeologists, photographers etc. Although it could be considered a blackbox software due to the minimum parameterization required for a $3 \mathrm{D}$ model generation, at the same time, it has proven its reliability while using algorithms like those close to the SIFT approach. Moreover, Photoscan supports a scripting engine (Python), giving the users the opportunity of project customization.

The image block orientation accuracy that is achieved, in any photogrammetric project, depends on the source data quality; hence, how robust the geometry of the image block is, and how many homologous points are identified on several photos. Overlapping between photos and strips was kept at a minimum of $80 \%$, even if additional oblique images were used for an ideal block geometry. Photos were captured by a SONY DSLR A700 camera, housed in its waterproof case.

2D plans were manually created from the orthophoto of each site, which was generated through the photogrammetric and visualization process. These were also augmented with archaeological information gathered from the site. Each wreck located, was evaluated by the archaeological team and artefacts were tagged on the sea bottom, before the photo acquisition process. Characteristic artefacts such as, the main types of amphorae from each wreck, small pottery, metal objects or wooden parts, were documented separately in situ, using conventional architectural documentation methods (Fig. 4), as well as photogrammetry when needed. Some of those were also brought to the surface for further study and detailed recording at the Ephorate of Underwater Antiquities in Athens. The 2D plans, included the detailed information that was gathered, such as recognition and localization of different types of amphorae and important artefacts, labelling of the artefacts, different materials that were found, characteristic depth measurements of the wreck site. 2D plans with such characteristics, updated daily, in many cases, prove to be the most useful tool for the archaeological research on site, and one of the main objectives of future work, is the automation of this process using the generated 3D models.

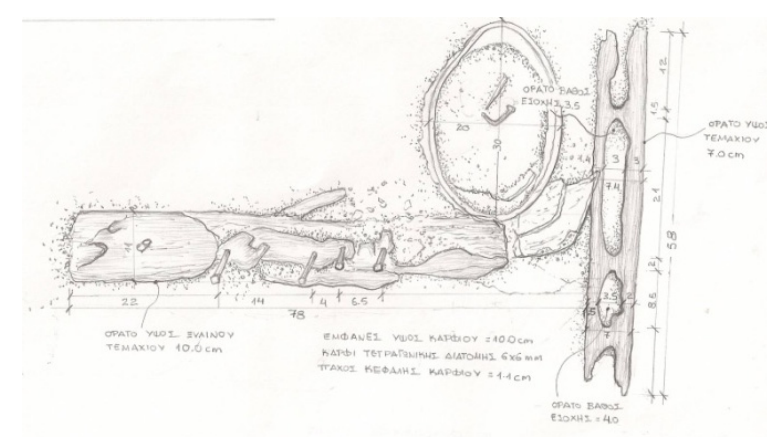

Figure 4: Detailed architectural documentation of important elements, Wreck No 6 , (C) H.I.M.A., F. Vlachaki

\subsubsection{Wreck No. 16}

Wreck No. 16 was found on the SE side of the Tripiti Reef at the NW end of the island of Makronisos, at depth of $39-44 \mathrm{~m}$, consisting of an accumulation of more than 150 surface amphorae, covering an area of $16 \mathrm{mX} 11 \mathrm{~m}$ which is interrupted by a rocky formation in the middle. Its cargo consists of at least three types of amphorae, Skerki Bank III, Dressel 2/4, Africaine, and is dated in the 4th Century AD (Koutsouflakis, 2013). On this site, the team encountered the problems of the restricted bottom time for the divers, as well as the accessibility of the wreck due to strong currents and surface winds. Therefore, the site area was bounded by 3 parallel ropes, so that the photographer could keep straight "flight" lines during image collection. Two scale bars and a submerged buoy gave a reference system to the object. Almost 300 images were aligned into photogrammetric software, resulting in the generation of an orthophotomosaic, a 3D textured model, and an orthophoto-based 2Dplan (Fig. $5)$.

\subsubsection{Wreck No. 17}

Wreck No. 17 was found at a distance of $90 \mathrm{~m}$, on the southern side of the Tripiti Reef, at the NW end of the island of Makronisos, at a depth of $38-40 \mathrm{~m}$. It is a small wreck on a steep rocky bottom with about 50 recorded artifacts in two different accumulations. Its cargo consists mainly of Dressel 2/4 and Dressel 5 type amphorae which estimate the date of the wreck in the 1st-2nd century AD (Koutsouflakis, 2013). A dataset of 50 images, which were aligned into photogrammetric software, was enough to generate an 
orthophotomosaic of the site (Fig. 6). No control points were established and measured. The scale of the object was defined only by three $1 \mathrm{~m}$ Plexiglas scale bars and the vertical axis was given by a submerged buoy.

\subsubsection{Wreck No. 18}

Wreck No. 18, dated in the 3rd-2nd century BC, was found $60 \mathrm{~m}$ south of a small peninsula on the east side of the island of Makronisos at a depth of 39-46m. It consists of a cargo of 120 surface amphorae of which the main concentration has a length of $20 \mathrm{~m}$ on a slanted but sandy bottom. Due to time and weather condition limitations, all data collection was completed in a few 15 minutes dives. A dataset of 180 images, were firstly enhanced, so that a satisfying amount of detected points on each image could be achieved, and then aligned. Products of the photogrammetric processing of the wreck were an orthophotomosaic, a textured DSM model, and an orthophoto-based 2D plan containing all labeled surface finds found in the site (Fig. 7).

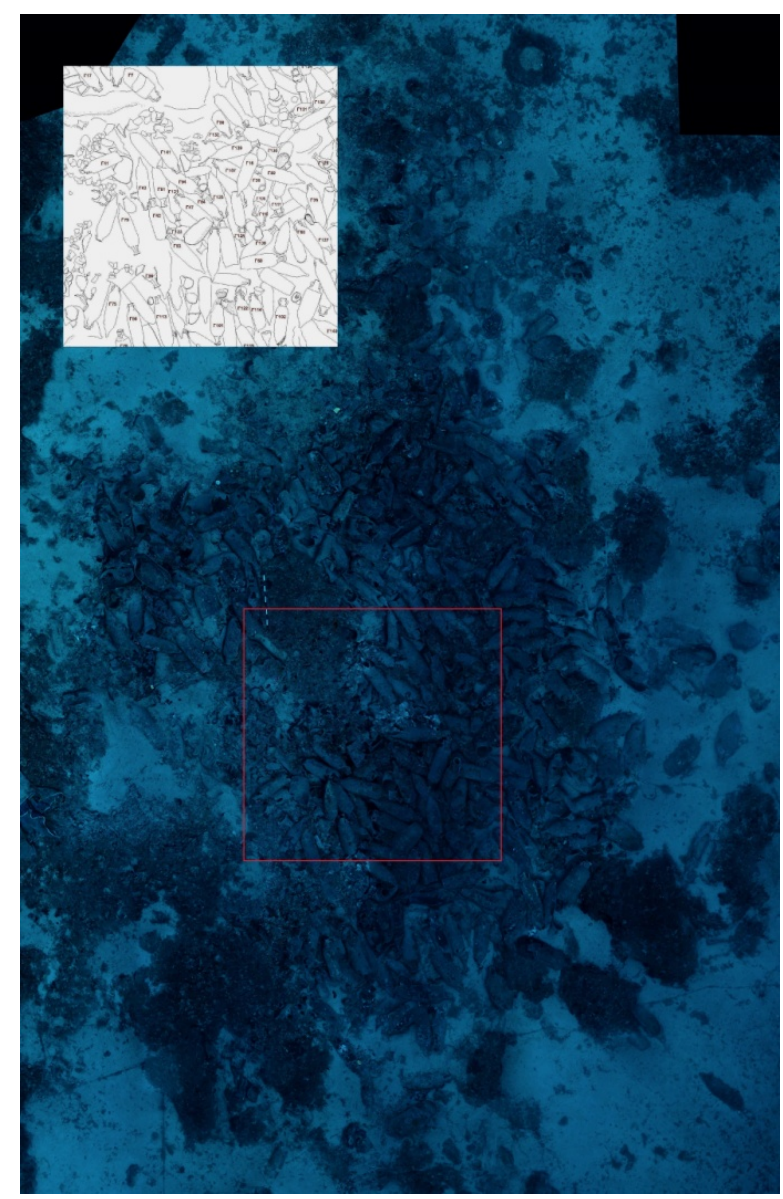

Figure 5: Orthophotomosaic and detail of the 2D drawing of wreck No.16, (C) H.I.M.A., E. Diamanti

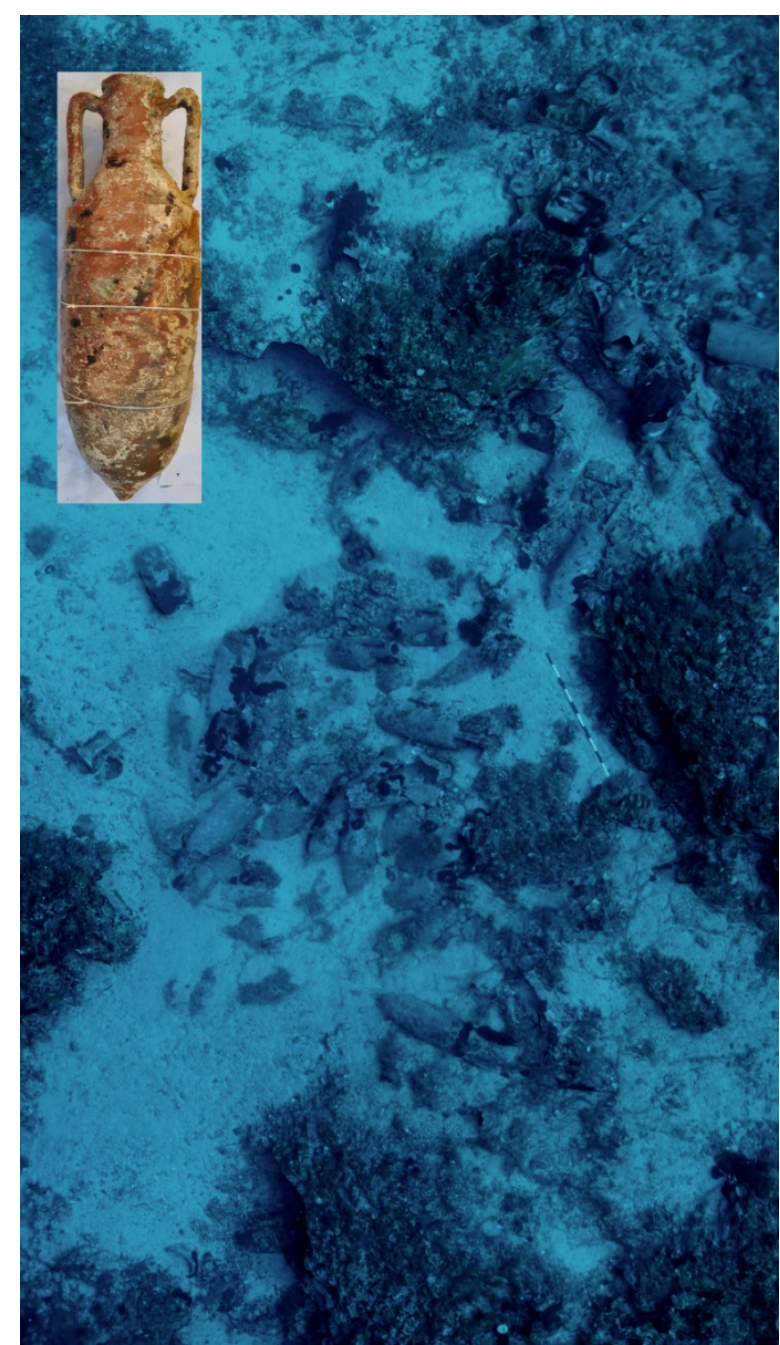

Figure 6: Detail of orthophotomosaic of wreck No.17 and main type of amphora found in the wreck, C H.I.M.A., E. Diamanti

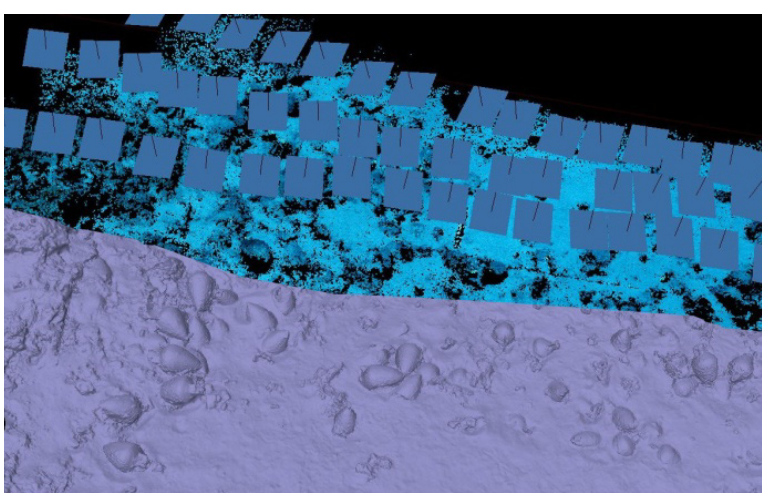

Figure 7: Detail of 3D shaded model, flight plan and point of wreck No.18, (C) H.I.M.A., E. Diamanti 


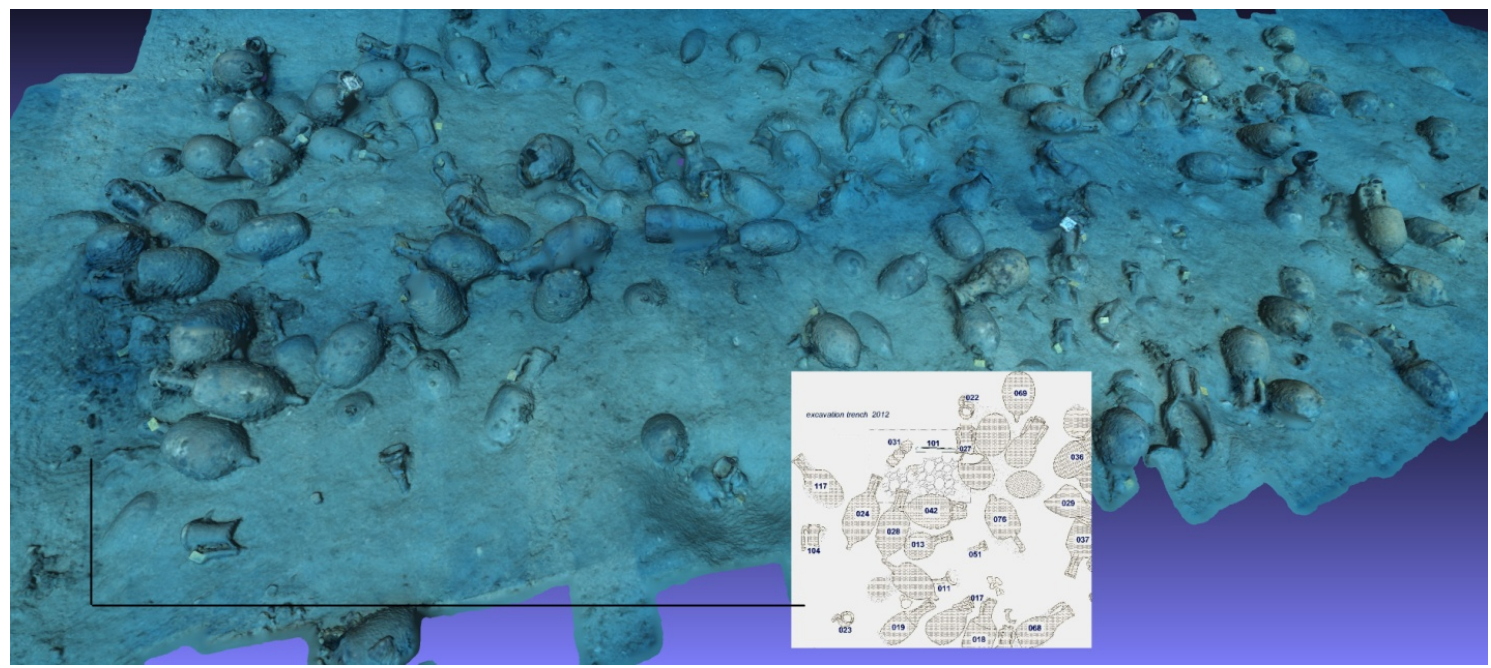

Figure 8: 3D textured model and detail of the 2012 excavation trench of Shipwreck N.24, C H.I.M.A., E. Diamanti

\subsubsection{Wreck No. 24}

Wreck No. 24 was found $50 \mathrm{~m}$ north of the cape that protects the small Vathy Avlaki gulf, on the east side of the island of Makronisos. It consists of an accumulation of different types of amphorae, lying on a slanted sandy bottom at a depth of $37-39 \mathrm{~m}$. The size of the concentrated cargo is $15 \mathrm{mX} 6 \mathrm{~m}$ with 120 documented surface artefacts, consisting of at least 6 types of amphorae, which date the wreck in the 2nd century BC (Koutsouflakis, 2013). This site was discovered two days before the closing of the 2012 underwater survey, and therefore a fast but complete $3 \mathrm{D}$ recording of the wreck was carried out. 145 images collected in one dive, were aligned, with the object's scale defined by two $1 \mathrm{~m}$ Plexiglas scale bars. The result was a textured 3D model and an orthophotomosaic. Most surface finds were labelled and a small $1 \mathrm{mX} 2 \mathrm{~m}$ trial trench was excavated. However, the importance of the site led the H.I.M.A. team to revisit the site in 2013. The results of the first 3D recording process had given accurate geometric and qualitative information about the wreck and had served as a tool in planning the second expedition on the site. A different approach to the $3 \mathrm{D}$ recording of the site was tested during the second season. Five control points were established, their coordinates were estimated by trilateration of tape measurements, and an aligned block of 160 vertical and oblique images was oriented. The final optimized block's bundle adjustment resulted in the generation of a dense point cloud and finally, a detailed textured 3D model (Fig.8), an orthophotomosaic and an orthophoto-based 2D plan of the wreck. Both documentation results, 2012 and 2013 surveys had to be georeferenced in a common reference system, so that changes of the site's situation (alterations of seabed, displacement of finds, cases of despoilment etc.) could be tracked. For this purpose, characteristic features of finds, such as cracks or edges, visible on both photographic sessions and well distributed across the wreck were selected and measured on the 2013's block. They were then transferred to the 2012's block of images which was reprocessed for the extraction of a new 3D model of the wreck. In this way, the two 3D models of two years' documentation procedures were able to be effectively compared.

\subsubsection{Wreck No. 26}

Wreck No. 26 was found at the exit of the bay of Gerolimnionas on the east side of the island of Makronisos, at a depth of $22-45 \mathrm{~m}$ consisting of a cargo of amphorae type Tripolitanian I, which dates the wreck in the 2nd century AD. All finds were found in a wide area at a geomorphologiacally rough sea-bed. Once again time limitations did not allow the establishment of any control points network, while the division of the site into two sub areas, posed an added difficulty in the acquisition of overlapping image datasets. Therefore, a second photo shoot was carried out from a further distance from the sea-bed, so that new images of smaller scale, could involve overlapping parts of the first dataset. A new block of 2 image datasets, consisting of 80 images in total, with an adequate geometry, was oriented, generating an orthophotomosaic based mostly on the geomorphology of the wreck's region.

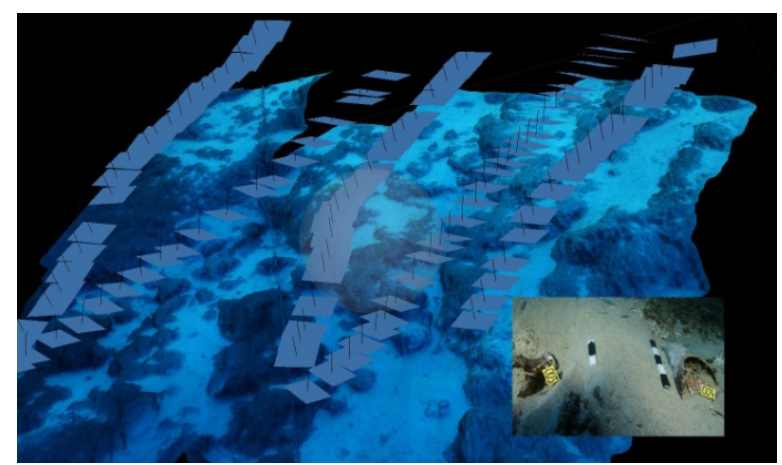

Figure 9: 3D shaded model, flight plan and image detail of wreck No.26, (C) H.I.M.A., E. Diamanti 


\section{CONCLUSIONS}

Evaluating the documentation results extracted from the underwater survey campaign in the South Euboean Gulf, it can be said that the advantage of applying photogrammetry is minimizing divers' bottom time using a low cost, high accuracy technique, for creating dense textured 3D models. In order to achieve these results certain criteria must be met, such as high quality images being collected under sufficient illumination and good visibility with precise pre-planned photo shooting. Time reduction of both underwater work and on land processing of results through photogrammetry has proven to be an important aid to "on site" underwater archaeological research.

Regarding future work, among the research interests of the team is to study how data acquisition, image processing and $3 \mathrm{D}$ reconstruction processing can be optimized through time and cost efficient procedures or products, both during survey and excavation campaigns. The presented case-studies could point to the need to follow and contribute to the development of user-friendly graphics environments, which would serve adequately the visualization needs of a large amount of acquired data. Also the development of semantically augmented, easily editable, 3D models could prove to be the most useful tool for "on site" work, both for surveys and excavations of underwater archaeological sites. Another important option would be the possibility of automatically extracting $2 \mathrm{D}$ vector annotated plans from the generated $3 \mathrm{D}$ models.

\section{ACKNOWLEDGEMENTS}

The underwater documentation team of the Hellenic Institute of Marine Archaeology (H.I.M.A) that completed the work on the presented case-studies includes, E. Diamanti (topographer), F. Vlackaki (architect), V. Mentogiannis (photographer), E. Koliva (architect), M. Garras (technical director), while work "on site" was supported by all the H.I.M.A. volunteers of the South Euboean Gulf Underwater Survey team with the collaboration of the helpful personnel of the Ephorate of Underwater Antiquities of Greece.

\section{REFERENCES}

Diamanti, E., Georgopoulos, A., \& Vlachaki, F., 2011.Geometric documentation of underwater archaeological sites. XIII CIPA international symposium, Prague, September 2011.

Drap, P., Underwater photogrammetry for archaeology. Special applications of photogrammetry, http://www.intechopen.com/books/special-applications-ofphotogrammetry/underwater-photogrammetry-forarchaeology, pp. 111-136, 2012.

Drap, P., Durand,, A., Provin, R., \& Long, L., 2005. Integration of multi-source spatial information and XML information system in underwater archaeology. Proceedings of the 20th International Symposium, CIPA 2005:
International Cooperation to Save the World's Heritage: Torino (Italy), 26 September - 1 October 2005 (Vol. 2).

Gawlik N., 2014. 3D modelling of underwater archaeological artefacts, Norwegian University of Science and Technology.

Koutsouflakis, G., 2013. Seafaring and Commercial Transport in the South Euboean Gulf (6th c. BC - 14th c. AD), unpublished $\mathrm{PhD}$ Thesis, University of Athens 2013.

McCarthy, J., \& Benjamin, J., 2014. Multi-image Photogrammetry for Underwater Archaeological Site Recording: An Accessible, Diver-Based Approach. Journal of Maritime Archaeology, 9(1), pp. 95-114.

Zhukovsky, M. O., Kuznetsov, V. D., \& Olkhovsky, S. V.,2013. Photogrammetric Techniques for 3-D Underwater Record of the Antique Time Ship from Phanagoria. ISPRSInternational Archives of the Photogrammetry, Remote Sensing and Spatial Information Sciences, 1(2), pp.717-721. 